Letter to Ediitor:

\title{
Domestic Violence and the CoVID-19 Crisis
}

\author{
Shirin Shahbazi Sighaldeh ${ }^{1}$, Shekoufeh Maleki $^{{ }^{*}}$ (iD
}

1. Department of Reproductive Health, Faculty of Nursing and Midwifery, Tehran University of Medical Sciences, Tehran, Iran.

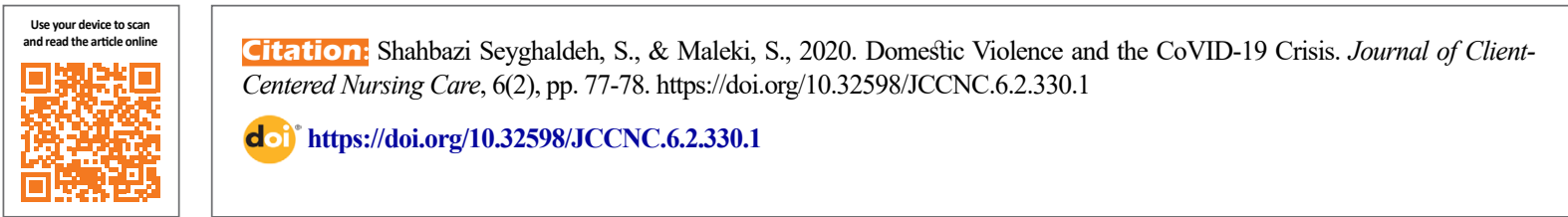

his letter intends to discuss how the coronavirus disease 2019 (COVID-19)

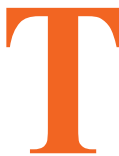
pandemic and its related preventive measures, such as maintaining social distance and reducing social and intimate relationships can affect the formation of domestic violence. It also points to the need for families to provide psychological support in dealing with this epidemic.

As the global pandemic of COVID-19 continues, countries, cities, and communities are taking more specific steps to slow down its spread (Campbell 2020). Domestic violence is another public health crisis that should be added to the effects of this new virus, as it flourishes like an opportunistic infection in epidemic situations (Taub 2020). Fear and insecurity, along with the epidemics, provide a suitable ground for different forms of violence (Usher et al. 2020).

Domestic violence refers to the threats or violent behaviors that occur within families, which could be physical, sexual, psychological, or economic, and may involve all family members, even children (Peterman 2020). Since measures, such as social isolation and home quarantine have been taken by governments, reports of domestic violence have increased worldwide (Campbell 2020). Although social isolation is critical to deal with epidemics, it gives more power to the aggressor. Social isolation, while limiting the availability of familiar supports, in creases the individual and collective vulnerabilities and makes it much harder for the victims to get help or escape. Preventive measures against the spread of COVID-19, including staying at home, avoiding social gatherings, teleworking, strict protective rules (at the community and family level), and restrictions on the use of food, clothing, and toilets as well as also avoiding (business or leisure) traveling, are among the factors that have been reported to be associated with an increase in the incidence of domestic violence. Thus, to reduce or prevent the occurrence of domestic violence during quarantine, it is necessary to take some actions, especially at the community level (Taub 2020; Usher et al. 2020) For example, mental health professionals are expected to provide psychological support to people, such as empathetic and non-judgmental listening, asking about their needs and concerns, endorsing people's experiences and feelings, safety upgrade, and referring people to the support services.

Information about available services (such as health center telephones) should be announced through social media, mass media, and health institutions. Governments and policymakers need to be aware of the increased risk of violence during the epidemic and emphasize the need to keep people in touch with each other (while taking precautions) and the importance of reporting any concerns about abuse (or violence).

* Corresponding Author:

Shekoufeh Maleki, M.Sc.

Address: Department of Reproductive Health, Faculty of Nursing and Midwifery, Tehran University of Medical Sciences, Tehran, Iran. Tel: +98 (21) 61054203

E-mail: shukofeh.mlky@gmail.com 
Maintaining social connections during quarantine is very important, especially with family or friends who are at risk of domestic violence (Usher et al., 2020).

Communities need to ensure that citizens are aware of the increased risk of domestic violence at this time. It is necessary to pay attention to the people so that they are not unaware of their neighbors and can report their concerns or problems to the appropriate authorities.

When domestic violence is neglected it will continue. We must be aware that the risk of domestic violence is very high at this moment, which also can remain for months in the future. Thus, people should be asked to report any violent behavior. "Your call may save a life" (Campbell 2020).

\section{Ethical Considerations}

\section{Compliance with ethical guidelines}

All ethical principles are considered in this article.

\section{Conflict of interest}

The authors declared no conflict of interest.

\section{Funding}

This research did not receive any grant from funding agencies in the public, commercial, or non-profit sectors.

\section{References}

Campbell, A. M., 2020. An increasing risk of family violence during the Covid-19 pandemic: Strengthening community collaborations to save lives. Forensic Science International: Reports, 2, p. 100089. [DOI:10.1016/j.fsir.2020.100089] [PMCID]

Peterman, A., et al., 2020. Pandemics and violence against women and children [Internet]. Cited 22 September 2020, https://www.cgdev.org/publication/pandemics-and-violence-against-women-and-children

Taub, A., 2020. new Covid-19 crisis: Domestic abuse rises worldwide [Internet]. Cited April 2020, https://www. nytimes.com/2020/04/06/world/coronavirus-domesticviolence.html

Usher, K., et al., 2020. Family violence and COVID-19: Increased vulnerability and reduced options for support. International Journal of Mental Health Nursing, 29(4), pp. 549-52. [DOI:10.1111/inm.12735] [PMID] [PMCID] 